\title{
Comparison of Vacuum Glazing Thermal Performance Predicted Using Two- and Three-Dimensional Models and Their Experimental Validation
}

\author{
Brian Norton \\ Technological University Dublin, brian.norton@tudublin.ie \\ Philip Eames \\ University of Warwick \\ Yueping Fang \\ University of Ulster
}

See next page for additional authors

Follow this and additional works at: https://arrow.tudublin.ie/dubencon2

Part of the Dynamics and Dynamical Systems Commons

\section{Recommended Citation}

Norton, B. et al (2008). Comparison of Vacuum Glazing Thermal Performance Predicted Using Two- and Three-Dimensional Models and Their Experimental Validation. ASME Summer Heat Transfer ConferenceJacksonville, Florida, 10-14 August.

This Conference Paper is brought to you for free and open access by the Dublin Energy Lab at ARROW@TU Dublin. It has been accepted for inclusion in Conference Papers by an authorized administrator of ARROW@TU Dublin. For more information, please contact arrow.admin@tudublin.ie, aisling.coyne@tudublin.ie, gerard.connolly@tudublin.ie.

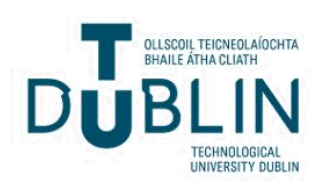


Authors

Brian Norton, Philip Eames, Yueping Fang, Trevor Hyde, and Neil Hewitt

This conference paper is available at ARROW@TU Dublin: https://arrow.tudublin.ie/dubencon2/73 
HT2008-56054

\section{COMPARISON OF VACUUM GLAZING THERMAL PERFORMANCE PREDICTED USING TWO AND THREE DIMENSIONAL MODELS AND THEIR EXPERIMENTAL VALIDATION}

\author{
Yueping Fang, Trevor J. Hyde, \\ Neil Hewitt \\ School of the Built Environment, \\ University of Ulster, BT37 OQB, \\ Newtownabbey, N. Ireland, UK
}

\author{
Philip C. Eames \\ School of \\ Engineering, \\ University of Warwick \\ CV4 7AL, UK
}

\author{
Brian Norton \\ Dublin Institute \\ of Technology, \\ Aungier Street, \\ Dublin2, Ireland
}

\section{ABSTRACT}

The thermal performance of vacuum glazing was predicted using two dimensional (2-D) finite element and three dimensional (3-D) finite volume models. In the 2-D model, the vacuum space, including the pillar arrays, was represented by a material whose effective thermal conductivity was determined from the specified vacuum space width, the heat conduction through the pillar array and the calculated radiation heat transfer between the two interior glass surfaces within the vacuum gap. In the 3-D model, the support pillar array was incorporated and modeled within the glazing unit directly. The difference in predicted overall heat transfer coefficients between the two models for the vacuum window simulated was less than $3 \%$. A guarded hot box calorimeter was used to determine the experimental thermal performance of vacuum glazing. The experimentally determined overall heat transfer coefficient and temperature profiles along the central line of the vacuum glazing are in very good agreement with the predictions made using the 2-D and 3-D models.

\section{INTRODUCTION}

As shown in Fig.1, vacuum glazing comprises two contiguously sealed glass panes with low emittance films on one or both glass surfaces with the vacuum gap, separated by an array of tiny support pillars to maintain the glass separation under atmospheric pressure. The first successfully fabricated vacuum glazing used a solder glass with a melting point of $450{ }^{\circ} \mathrm{C}$ to seal the periphery of the vacuum gap [1]. This high temperature prohibited the use of tempered glass and restricted the range of soft low emittance coatings due to thermal degradation that resulted at this temperature. These restrictions are removed by using a low temperature edge sealing process and an indium based edge seal with a low melting point of less than $200{ }^{\circ} \mathrm{C}$ developed and patented by the University of Ulster $[2,3]$.

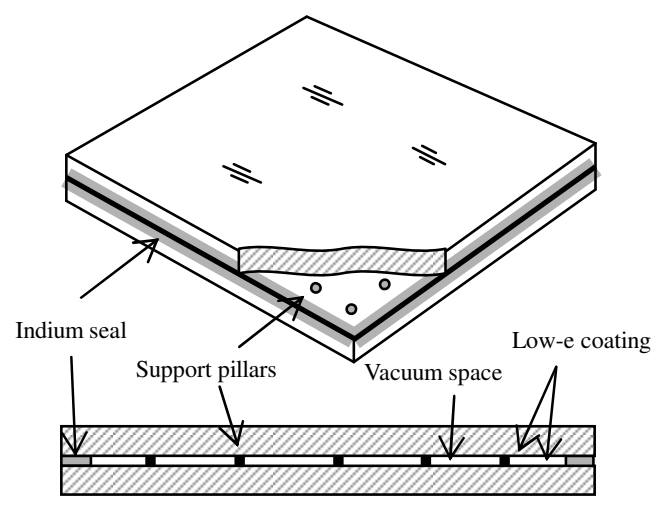

Fig. 1 Schematic diagram of vacuum glazing

Two-dimensional (2-D) finite element models have been used to simulate the thermal performance of double glazing window systems, which have been validated experimentally $[4,5,6]$. The critical aspect when utilising a 2-D model to simulate the thermal performance of double glazing is the determination of the heat transfer coefficients between the two internal glass surfaces bounding the evacuated space. In this work, the vacuum space, including the pillar arrays, was represented by a material whose effective thermal conductivity was determined from the specified vacuum space width, the heat conduction through the pillar array and 
the calculated radiation heat transfer between the two internal glass surfaces within the vacuum gap. Heat flow across a full vacuum glazing is a combined function of heat conduction through the support pillars and edge seal, radiative heat flow between the two glass panes and convection and conduction in the residual gas within the vacuum space. In a successful sample whose vacuum pressure is less than $0.1 \mathrm{~Pa}$, the effects of any residual gas are insignificant [7].

A three-dimensional (3-D) finite volume model was developed to simulate the thermal performance of vacuum glazing with the support pillar array incorporated and modeled directly [8]. The circular cross section of the pillar in the fabricated system is replaced by a square cross section pillar of equal area in the model. A graded mesh is used with a high density of nodes in and around the pillar to provide adequate representation of the heat transfer. The predicted difference in overall heat transfer coefficients between the two models for the vacuum window simulated was investigated.

A guarded hot box calorimeter [9] was used to determine the thermal performance of vacuum glazing. The experimentally determined heat conductance and temperature profiles along the central line of the vacuum glazing were in very good agreement with the predictions made using the 2-D and 3-D models.

\section{NOMENCLATURE}

$\begin{array}{ll}a & \text { Pillar radius }(m) \\ A & \text { Area of test sample }\left(\mathrm{m}^{2}\right) \\ C & \text { Thermal conductance }\left(\mathrm{Wm}^{-2} \mathrm{~K}^{-1}\right) \\ h & \text { Surface heat transfer coefficient }\left(\mathrm{Wm}^{-2} \mathrm{~K}^{-1}\right) \\ k & \text { Thermal conductivity }\left(\mathrm{Wm}^{-1} \mathrm{~K}^{-1}\right) \\ P & \text { Vacuum pressure }(\text { Pascal }) \\ s & \text { Pillar separation }(\mathrm{m}) \\ T & \text { Temperature }\left({ }^{\circ} \mathrm{C}\right) \\ \text { Greek } & \text { letters } \\ \varepsilon & \text { Emittance of surface } \\ \sigma & \text { Stefan-Boltzmann constant }\left(5.67 \times 10^{-8} \mathrm{Wm}^{-2} \mathrm{~K}^{-4}\right) \\ \text { Subscripts } \\ 1,2 & \text { Refers to surfaces in hot and cold chambers } \\ b & \text { Metering box } \\ e & \text { Flanking loss } \\ m & \text { Mask wall } \\ n & \text { Environment temperature } \\ \mathrm{s} & \text { Specimen } \\ g-g & \text { Glass to glass }\end{array}$

\section{2-D FINITE ELEMENT MODEL APROACH}

In the finite element model developed to simulate the heat transfer through vacuum glazing, the Galerkin approach was used with eight-node isoparametric elements. The detailed description of the finite element model employed is available elsewhere $[9,10]$. The evacuated gap was treated as a material whose thermal conductivity was equal to the combined thermal conductivity of support pillar array and the long wave radiative heat transfer between the two internal glass surfaces within the vacuum space. Significant interactions between heat conductance through the pillars and radiation between the two internal glass surfaces exist. However when compared to the total heat flow through the overall glazing system, the influence of the interaction is small and can be ignored. The total thermal conductance can be determined by [7]:

$$
\begin{aligned}
& C_{g-g \text {, centre-of-glazing }}=C_{g-g, \text { gas }}+C_{g-\text { g, radiation }}+C_{g-\text {-g,pillars }} \\
& \quad=0.8 P+4 \varepsilon_{\text {effective }} \sigma T_{\text {average }}^{3}+2 K_{\text {glass }} a / s^{2}
\end{aligned}
$$

where $P$ is the internal pressure measured in Pascals. For a successfully fabricated vacuum glazing, the $P$ is less than $0.1 \mathrm{~Pa}$, so the heat conductance of residual gas can be ignored. $\sigma$ is the Stefan Boltzmann constant $\left(5.67 \times 10^{-8} \mathrm{Wm}^{-}\right.$ $\left.{ }^{2} \mathrm{~K}^{-4}\right), T_{\text {average }}$ is the average of the glass pane temperatures $T_{l}$ and $T_{2}$ and the effective emittance, $\varepsilon_{\text {effective }}$, is calculated from the surface emittance $\varepsilon_{1}$ and $\varepsilon_{2}$ by:

$$
\frac{1}{\varepsilon_{\text {effective }}}=\frac{1}{\varepsilon_{1}}+\frac{1}{\varepsilon_{2}}-1
$$

Theoretically the emittance value depends on the surface temperature, the wavelength, the angle of incidence of the radiation to the normal [11]. Equation 3 was assumed to be independent of these parameters, which resulted in an error of $4 \%$ [11].

\section{3-D FINITE VOLUME MODEL}

The finite volume model (FDM) employed leads to a sparse well structured system of equations that can be efficiently solved. This enables a large number of volumes to be employed to represent the vacuum glazing geometry and allow the direct representation of the small pillars. The equation bandwidth using the finite volume method is smaller than that obtained for the finite element method using 20 node brick elements and consequently requires fewer numeric operations and less CPU time to obtain a satisfactory solution. Due to symmetry conditions, only one quarter of the vacuum glazing was simulated to represent the whole glazing system under the conditions of an ASTM [12] experimental test. In the 3-D finite volume model, the support pillars were integrated and modelled into the complete system for ease of computation in the simulation. 
The cylindrical pillars employed in fabricated systems were replaced by the same number of cubical pillars with the same areas of the cross sections, since the both pillar shapes conduct similar amounts of heat under the same boundary conditions [13]. The length of the square base of each cubical pillar is $\sqrt{\pi} a$, where $a$ is the radius of the equivalent cylindrical pillar. A graded mesh is used with a high density of nodes in and around each pillar to provide adequate representation of the heat transfer.

In order to test the accuracy of simulations with specified mesh number, the thermal performance of a small central area $(25 \mathrm{~mm}$ by $25 \mathrm{~mm})$ with a single pillar in the centre was simulated using a mesh of $50 \times 50 \times 25$ nodes. The mesh was denser in the area close to the pillar. The 25 nodes were distributed in a graded mesh through the glazing thickness of $8.12 \mathrm{~mm}$. The thermal conductance of this simulated unit with a pillar in the centre was in good agreement with the analytic prediction with $1.5 \%$ variation, which is comparable to the result of Wilson et al [14]. This level of agreement indicates that the density of nodes is sufficient to simulate the realistic level of heat flow with high accuracy.

\section{COMPARISON OF THERMAL PERFORMANCE SIMULATED UNDER ASTM BOUNDARY CONDITIONS}

In the simulations, the assumed indoor air set-point temperature and outdoor ambient air temperatures were set to be constant at $21.1{ }^{\circ} \mathrm{C}$ and $-17.8{ }^{\circ} \mathrm{C}$ respectively, the total heat transfer coefficients on the indoor and outside surfaces were set to be 8.3 and $30 \mathrm{Wm}^{-2} \mathrm{~K}^{-1}$ respectively corresponding to those in relevant ASTM measurement standards for glazings in winter conditions [12]. The simulated vacuum glazing was $0.4 \mathrm{~m}$ by $0.4 \mathrm{~m}$ in size and comprised two $4 \mathrm{~mm}$ thick low-emittance film coated glass panes, separated by $0.12 \mathrm{~mm}$, supported by a $0.32 \mathrm{~mm}$ diameter pillars, spaced at $25 \mathrm{~mm}$ in a regular square pattern. The edge seal was a $6 \mathrm{~mm}$ wide band of indium metal. No frame insulation was used. The isotherms on the cold and hot side surfaces of the vacuum glazing were predicted and presented in Fig. 2. The temperature profiles along lines AA, $\mathrm{BB}$ and $\mathrm{CC}$ in Fig. 2 are presented in Fig. 3.

It can be seen from Fig. 3 that the temperature profiles predicted by the 2-D and 3-D models along lines AA and BB are in very good agreement with each other with a maximum deviation of 3\%. The 3-D temperature profile on the hot side along the line $\mathrm{CC}$ deviates from the 2-D temperature profiles by $15 \%$. Comparing the temperature profiles predicted by the 3-D model along the lines $\mathrm{AA}$ and $\mathrm{BB}$, it can be seen that the temperature variation due to heat conduction through the support pillars on the central glazing area is 0.35 ${ }^{\circ} \mathrm{C}$ and $0.37{ }^{\circ} \mathrm{C}$ on the cold and hot side surfaces respectively. It can be seen that the temperature variations on the hot side is greater than the cold side. Comparing the temperature profiles along the line $\mathrm{CC}$ on the hot and cold side surfaces, it is seen that the temperature variations on the line $\mathrm{CC}$ on the cold side is much closer to the temperature profiles on the lines AA and BB. This is caused by the difference in the convective heat transfer coefficients on the hot and cold sides of the glass surfaces. The detailed analysis can be seen in Fang et al [15]. The characteristic distance $l=\sqrt{k t / h}$ [16] on the hot side is significantly greater than that on the cold side surface.

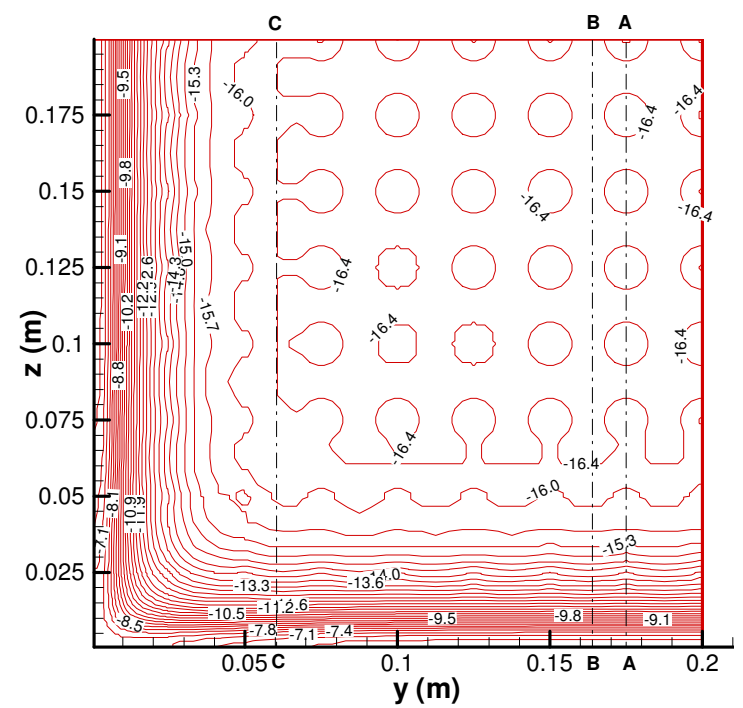

(a)

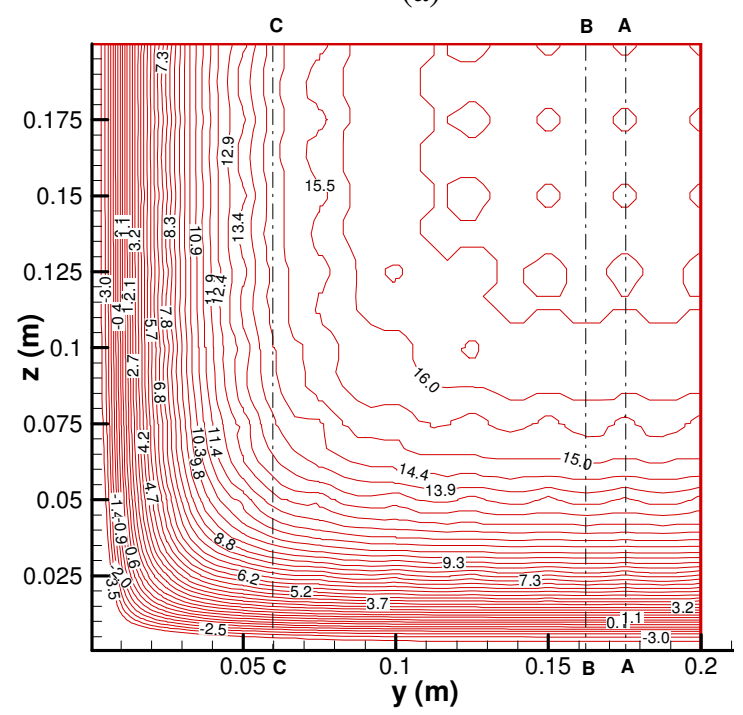

(b)

Fig. 2 Predicted isotherms of vacuum glazing on the cold (a) and hot (b) surfaces intercepted from the 3-D isotherms. No frame insulation was used. 


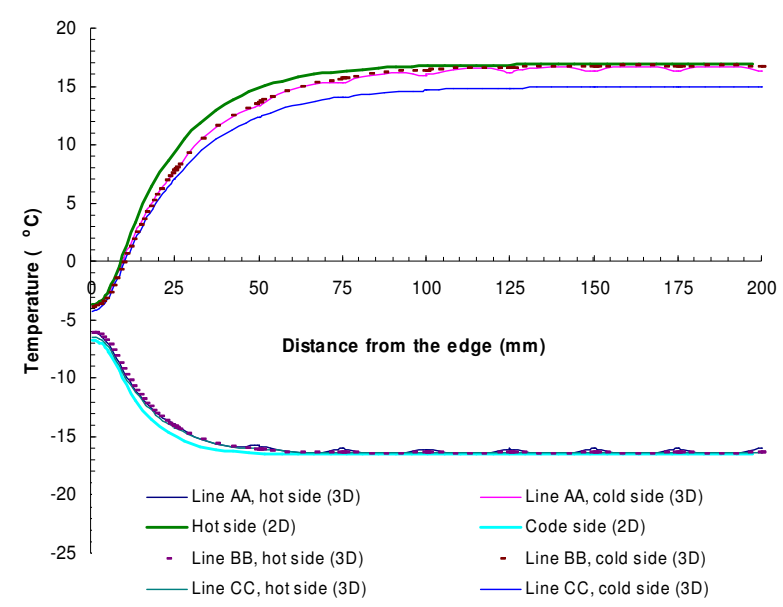

Fig. 3 Predicted temperature profiles predicted by the 2-D and 3-D models along the lines $\mathrm{AA}, \mathrm{BB}$ and $\mathrm{CC}$ as shown in Fig. 2.

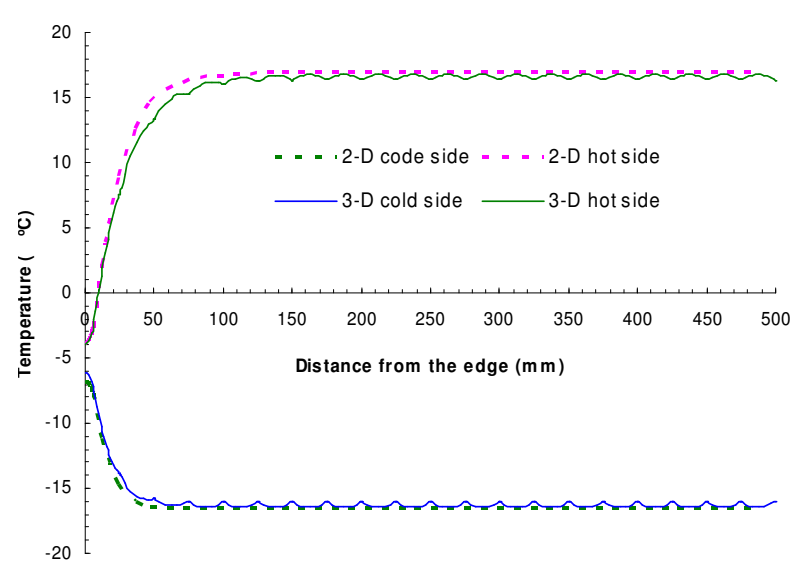

Fig. 4 Temperature profiles predicted by 2-D and 3-D models for a $1 \mathrm{~m}$ by $1 \mathrm{~m}$ vacuum glazing under ASTM boundary conditions at the line AA above the pillar array.

Temperature profiles of a vacuum glazing with dimensions of $1 \mathrm{~m}$ by $1 \mathrm{~m}$ were calculated using the 2-D and 3-D models. As presented in Fig. 4, the temperature profiles of the $1 \mathrm{~m}$ by $1 \mathrm{~m}$ vacuum glazing simulated by the 2-D and 3 -D models are in very good agreement. The error between the two temperature profiles is less than $2 \%$ in the centre glazing area and 5\% in the edge area. The agreement of the two temperature profiles of $1 \mathrm{~m}$ by $1 \mathrm{~m}$ sample predicted by the 2-D and 3-D models is better than that of $0.4 \mathrm{~m}$ by $0.4 \mathrm{~m}$ samples. This is because the edge effect on the small sample is greater than that of the larger sample.

For a $0.4 \mathrm{~m}$ by $0.4 \mathrm{~m}$ vacuum glazing without frame insulation, the heat conductance of the centre glazing area predicted by the 2-D and 3-D models were 1.17 and 1.19 $\mathrm{Wm}^{-2} \mathrm{~K}^{-1}$, the deviation between the two results was less than $1.7 \%$. The conductance of the total glazing area predicted by the 2-D and 3-D models were 2.10 and $2.16 \mathrm{Wm}^{-2} \mathrm{~K}^{-1}$, the deviation was $2.8 \%$.

For the $1 \mathrm{~m}$ by $1 \mathrm{~m}$ sample, the heat conductance of the centre glazing area predicted by the 2-D and 3-D models were 1.07 and $1.08 \mathrm{Wm}^{-2} \mathrm{~K}^{-1}$, the deviation was less than $0.9 \%$. The heat conductance of the total glazing area predicted by the 2-D and 3-D models were 1.41 and 1.43 $\mathrm{Wm}^{-2} \mathrm{~K}^{-1}$, the deviation was $1.4 \%$. The heat conductance predicted by the 2-D and 3-D models has a better agreement in the centre glazing area than that of the total glazing area; the $1 \mathrm{~m}$ by $1 \mathrm{~m}$ sample has a better agreement in predicted heat conductance by the 2-D and 3-D models than for the $0.4 \mathrm{~m}$ by $0.4 \mathrm{~m}$ glazing. The conductance of the centre glazing area of the $0.4 \mathrm{~m}$ by $0.4 \mathrm{~m}$ vacuum glazing was $8.5 \%$ greater than that of the $1 \mathrm{~m}$ by $1 \mathrm{~m}$ sample due to conductance through the edge seal having a larger effect on the small sample compared to the larger sample. Lateral heat conduction along the glass panes still has considerable influence to the heat conductance of centre glazing area for the $0.4 \mathrm{~m}$ by $0.4 \mathrm{~m}$ sample. For the $0.4 \mathrm{~m}$ by $0.4 \mathrm{~m}$ vacuum glazing with a solid wood frame with $20 \mathrm{~mm}$ rebate depth, its heat conductance of the centre glazing area is $3 \%$ greater than that of the $1 \mathrm{~m}$ by $1 \mathrm{~m}$ vacuum glazing with $20 \mathrm{~mm}$ frame rebate depth [8] under ASTM winter conditions. The frame significantly reduces the lateral heat conduction along the glass panes due to heat conductance through the edge seal.

\section{EXPERIMENTAL MEASUREMENTS OF THE THERMAL PERFORMANCE OF VACUUM GLAZING}

In accordance with the specification of the relevant ISO standard [17], a guarded hot box calorimeter as shown in Fig. 5 was designed and constructed at the University of Ulster to determine the thermal performance of vacuum glazing fabricated using the low temperature edge sealing technique $[9,17]$. The heat flow across the vacuum glazing was determined by

$$
Q_{s}=Q_{\text {input }}-Q_{e}-Q_{m}
$$

where $Q_{\text {input }}$ is the input heat generated by an electric heater, whose power was determined with an uncertainty of $0.2 \%$, $Q_{e}$ is the flanking loss determined by the finite element model, $Q_{m}$ is the heat flow across the mask wall determined by:

$$
Q_{m}=A_{m} k_{m}\left(T_{m 1}-T_{m 2}\right)
$$

where $A_{m}$ is the mask wall area within the metering box, $T_{m l}$ and $T_{m 2}$ are mask wall surface temperatures measured by thermocouples located in the hot and cold boxes, $k_{m}$ is the 
heat conductivity of the Styrofoam mask wall, which has been calibrated as the function of its mean temperature. The detailed process of this calibration has been reported in Fang et al [9]. The heat conductance of a vacuum glazing specimen with an area $A_{s}$ was determined from:

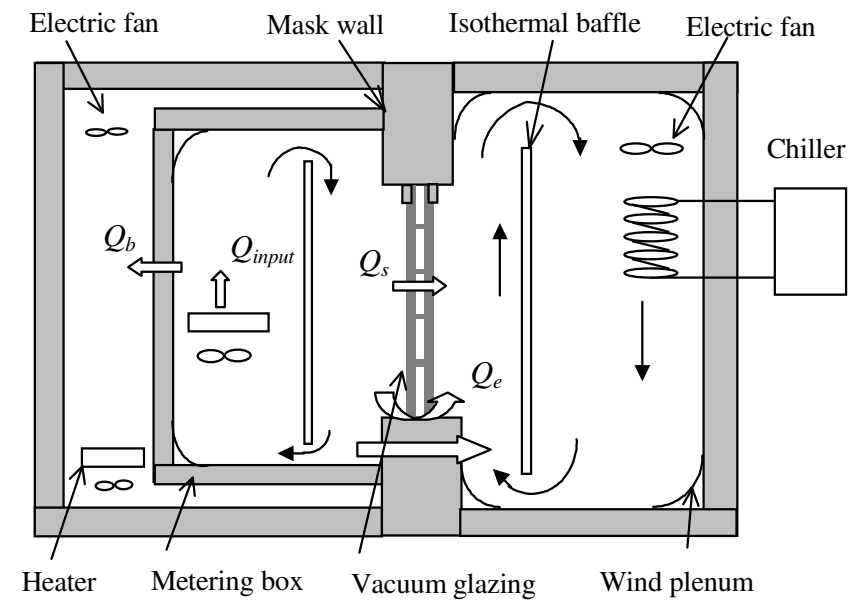

Fig. 5 Schematic diagram of guarded hot box calorimeter

$$
C=\frac{Q_{s}}{A\left(T_{s 1}-T_{s 2}\right)}
$$

where $T_{s 1}$ and $T_{s 2}$ are the specimen surface temperatures as measured by thermocouples. An environmental temperature $T_{n}$ is recommended [17] to combine radiant and air temperatures to represent the proper weighting of air and radiant temperatures, to determine the heat flow to the surface:

$$
T_{n}=\frac{T_{a} \frac{Q_{s}}{A}+\varepsilon h_{r}\left(T_{a}-T_{r}\right) T_{s}}{\frac{Q_{s}}{A}+\varepsilon h_{r}\left(T_{a}-T_{r}\right)}
$$

where $T_{r}$ and $T_{a}$ are the baffle surface and air temperatures respectively, $\varepsilon$ is the emittance and $h_{r}$ is the radiation coefficient. Using equation 7 , in the hot and cold chambers, $T_{n 1}$ and $T_{n 2}$ can be calculated, subsequently the surface heat transfer coefficient of the hot and cold sides were determined by equations 8 and 9:

$$
\begin{aligned}
& h_{1}=\frac{Q_{s}}{A\left(T_{n 1}-T_{1}\right)} \\
& h_{2}=\frac{Q_{s}}{A\left(T_{2}-T_{n 2}\right)}
\end{aligned}
$$

In the experimental test, the input power of the electric heater in the hot box was $12.6 \mathrm{~W}$, the air temperatures in the hot and cold boxes were $27.4{ }^{\circ} \mathrm{C}$ and $7.9{ }^{\circ} \mathrm{C}$ respectively. The mean surface temperatures of the mask wall at the hot and cold sides were $27.3{ }^{\circ} \mathrm{C}$ and $8.1{ }^{\circ} \mathrm{C}$. The surface heat transfer coefficients of the mask wall on the hot and cold sides were 12.0 and $22.0 \mathrm{Wm}^{-2} \mathrm{~K}^{-1}$. The glass mean surface temperatures of the glass sheets were $23.7{ }^{\circ} \mathrm{C}$ and $9.6^{\circ} \mathrm{C}$. The surface heat transfer coefficients of the glazing surfaces at the hot and cold sides were 5.65 and $12.78 \mathrm{Wm}^{-2} \mathrm{~K}^{-1}$. The experimentally determined heat conductance of the centre and total vacuum glazing area were 1.10 and $1.22 \mathrm{Wm}^{-2} \mathrm{~K}^{-1}$. The detailed calculation method is described elsewhere [8].

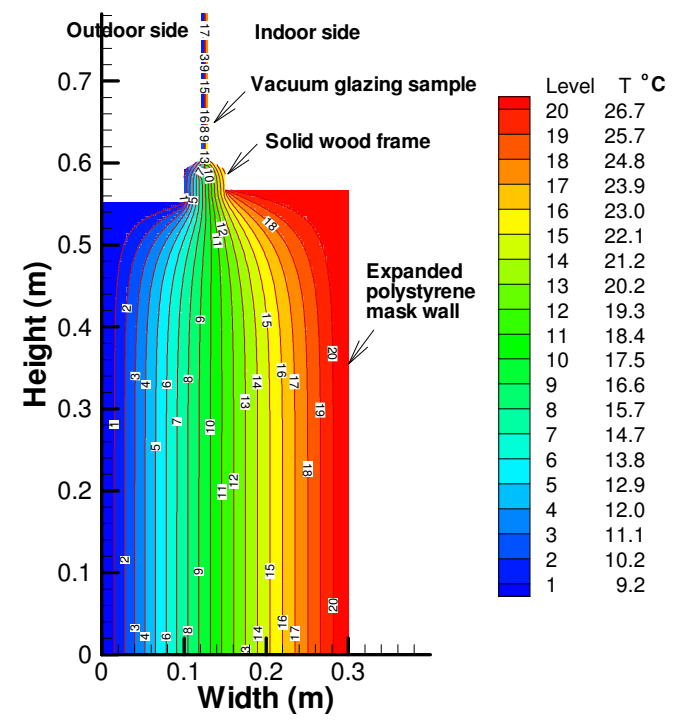

(a)

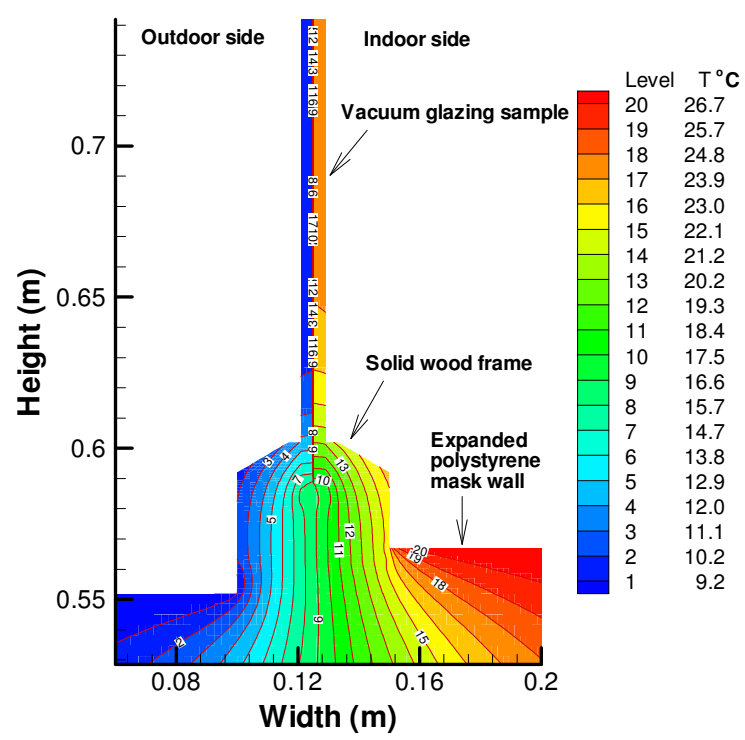

(b)

Fig. 6 (a) Predicted isotherms of mask wall with vacuum glazing; (b) Enlarged view of the vacuum glazing rebated into a solid wood frame. 


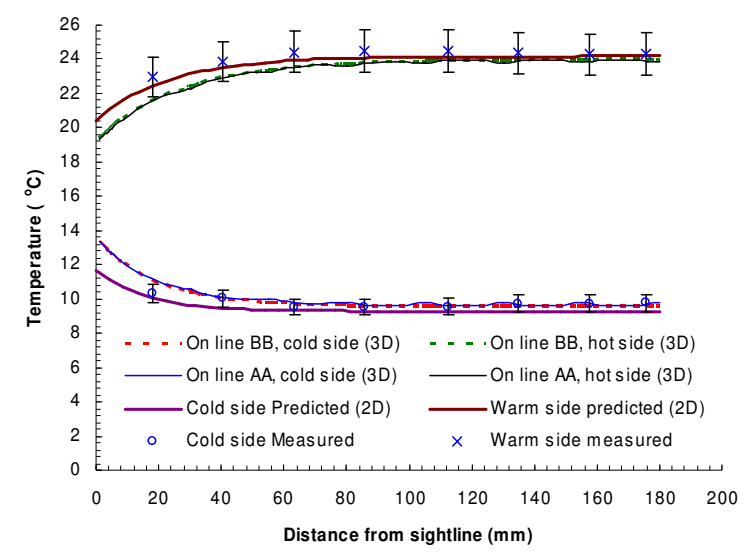

Fig. 7 Comparison of the experimentally determined temperature profiles along the lines AA on the glazing surface to those predicted by the 2-D and 3-D models.

Using the boundary conditions of the experimental test and the finite element model, the predicted isotherms of the mask wall and enclosed vacuum glazing were calculated and are presented in Fig. 6 (a). The enlarged view across the frame area is shown in Fig. 6 (b). In both figures, the temperature gradient across the mask wall and vacuum glazing can be seen clearly. In Fig. 6 (b) the flanking loss across the edge area of mask wall was determined to be $1.64 \mathrm{~W}$. The thermal conductivity of the wood used for the frame was $0.166 \mathrm{Wm}^{-1} \mathrm{~K}^{-1}$ [13]. The measured and predicted temperature profiles by both 2-D and 3-D models along the central line AA of vacuum glazing are compared in Fig. 7, in which very good agreement between the predictions and measured results can be seen. The error bars of the measured temperature profiles represent $5 \%$ uncertainty. The temperature variations due to the heat conduction of the pillars are $0.2{ }^{\circ} \mathrm{C}$ in the centre glazing area. This is less than that of $0.4{ }^{\circ} \mathrm{C}$ simulated under ASTM conditions, in which the air temperature difference between the inside and outside environments is greater than the practical experimental conditions.

The heat conductance of the centre glazing areas were determined to be $1.10 \mathrm{Wm}^{-2} \mathrm{~K}^{-1}$ by the 2-D model and 1.11 $\mathrm{Wm}^{-2} \mathrm{~K}^{-1}$ by the 3-D model, the deviation was less than $0.9 \%$. The heat conductance of the total glazing areas were determined to be $1.21 \mathrm{Wm}^{-2} \mathrm{~K}^{-1}$ by the 2-D model and 1.23 $\mathrm{Wm}^{-2} \mathrm{~K}^{-1}$ by the $3-\mathrm{D}$ model, the deviation was $1.6 \%$. If the vacuum glazing is rebated within an insulation frame, the agreement of the heat conductance predicted by the 2-D and 3-D models is significantly better than that of the glazing without an insulation frame. Comparing Figs. 3 and 7, it can be seen that the frame insulation significantly changed the temperature profiles at the edge area, leading to a reduction of the deviation between the heat conductances predicted by the 2-D or 3-D models.

\section{Conclusions}

The thermal performance of vacuum glazing predicted using the 2-D and 3-D models with ASTM boundary conditions are compared and the predictions experimentally validated. The investigated vacuum glazing consisted of two $4 \mathrm{~mm}$ thick glass panes with low emittance coatings of emittance 0.18 , separated by an array of support pillars with a diameter of $0.32 \mathrm{~mm}$ and height of $0.12 \mathrm{~mm}$, spaced at 25 $\mathrm{mm}$. It was found that the agreement of the heat conductance and temperature profiles of the $1 \mathrm{~m}$ by $1 \mathrm{~m}$ vacuum glazing predicted by the 2-D and 3-D models is better than that of the $0.4 \mathrm{~m}$ by $0.4 \mathrm{~m}$ vacuum glazing. For the $0.4 \mathrm{~m}$ by $0.4 \mathrm{~m}$ vacuum glazing without frame insulation, the heat conductance of the centre glazing area were determined to be 1.17 and $1.19 \mathrm{Wm}^{-2} \mathrm{~K}^{-1}$ by the 2-D and 3-D models with a deviation of $1.7 \%$; the total glazing conductance predicted the 2-D and 3-D models were 2.10 and $2.16 \mathrm{Wm}^{-2} \mathrm{~K}^{-1}$ by the 2-D and 3-D models with a deviation of $2.8 \%$. For the $1 \mathrm{~m}$ by $1 \mathrm{~m}$ sample without frame insulation, the heat conductance of the centre glass areas predicted by the 2-D and 3-D models were 1.07 and $1.08 \mathrm{Wm}^{-2} \mathrm{~K}^{-1}$ with a deviation of $0.9 \%$ and those of the total glazing areas were 1.41 and $1.43 \mathrm{Wm}^{-2} \mathrm{~K}^{-1}$ by the 2-D and 3-D models with a deviation of $1.4 \%$. The heat conductance of the centre of glazing area of $0.4 \mathrm{~m}$ by $0.4 \mathrm{~m}$ vacuum glazing without an insulating frame was greater by $8.5 \%$ than that of $1 \mathrm{~m}$ by $1 \mathrm{~m}$ vacuum glazing without an insulating frame due to the edge effects on the smaller sample being greater than on the larger sample. For the $0.4 \mathrm{~m}$ by $0.4 \mathrm{~m}$ and $1 \mathrm{~m}$ by $1 \mathrm{~m}$ vacuum glazing samples with an insulating frame with $20 \mathrm{~mm}$ rebate depth under ASTM conditions, the difference in heat conductance of the centre glazing areas was 3\% [8]. The agreement of heat conductance at the centre glazing area is better than that for the total glazing area. The temperature profiles on the glazing surfaces predicted by the 2-D and 3$\mathrm{D}$ models are in excellent agreement with deviations of $3 \%$ for $0.4 \mathrm{~m}$ by $0.4 \mathrm{~m}$ glazing at the centre glass area and $2 \%$ for the $1 \mathrm{~m}$ by $1 \mathrm{~m}$ glazing. In the edge area the deviations were $10 \%$ for $0.4 \mathrm{~m}$ by $0.4 \mathrm{~m}$ glazing and $5 \%$ for the $1 \mathrm{~m}$ by $1 \mathrm{~m}$ glazing.

For the experimental conditions used in this work, for a solid wood frame with a rebate of $20 \mathrm{~mm}$, the heat conductance of the centre glazing areas predicted with the 2$\mathrm{D}$ and 3-D models were 1.10 and $1.11 \mathrm{Wm}^{-2} \mathrm{~K}^{-1}$ by the $2-\mathrm{D}$ and 3-D models with a deviation of $0.9 \%$ and those of the total glazing 1.21 and $1.23 \mathrm{Wm}^{-2} \mathrm{~K}^{-1}$ with a deviation of $1.6 \%$. The experimentally determined heat conductance was in good agreement with the predictions made using the 2-D and 3-D models within an uncertainty of less than 5\%. These results demonstrate that for vacuum glazing in which the edge is rebated in an insulating frame, there is a 
significantly reduced deviation between the heat conductance predicted by the 2-D and 3-D models.

These results would indicate that the 2-D model is sufficient for predicting heat transfer and surface temperatures in the centre-region of vacuum glazing with areas larger than $1 \mathrm{~m}$ by $1 \mathrm{~m}$. For small areas, rectangular panes (with a side of less than $1 \mathrm{~m}$ length) and for detailed studies of behavior at the edge seal and pillars, acceptable accuracy in predicting heat transfer and surface temperatures is only provided by the use of a full 3-D model. For vacuum glazing systems of dimensions $1 \mathrm{~m}$ by $1 \mathrm{~m}$ or larger, the effect of the edge area in which larger temperature gradients occur is less influential on total window performance than the central area. For the $0.4 \mathrm{~m}$ by $0.4 \mathrm{~m}$ sample, the 3dimentional edge and corner effects are significant, this leads to a greater divergence in the heat conductance calculated by the 2-D and 3-D models.

\section{ACKNOWLEDGMENTS}

The authors acknowledge the support from the Charles Parson Energy Research Awards through the National Development Plane 2007-2013 of the Department of Communications, Marine and Natural Resources, Dublin, Ireland.

\section{REFERENCES}

[1] S. J. Robinson and R.E. Collins, Evacuated windowstheory and practice, ISES Solar World Congress, International Solar Energy Society, (1989) Kobe, Japan.

[2] P. W. Griffiths, Di M. Leo, P. Cartwright, P.C. Eames, P. Yianoulis, G. Leftheriotis and B. Norton, Fabrication of evacuated glazing at low temperature. Solar Energy 63, 243249 (1998).

[3] T. J. Hyde, P. W. Griffiths, P.C. Eames and B. Norton, Development of a novel low temperature edge seal for evacuated glazing. In Proc. World Renewable Energy Congress VI (WREC2000), Brighton, U.K. pp. 271-274.

[4] A. H. Elmahdy, Th. Frank, Heat transfer at the edge of sealed insulating glass unit: comparison of hot box measurements with finite-difference model. ASHRAE Transactions: Symposia 915-922 (1993).

[5] J. L. Wright, H. F. Sullivan, A two-dimensional numerical model for glazing system thermal analysis. ASHRAE Transactions: Symposia 819-831 (1995).

[6] D. Curcija D, W. P. Goss, Two-dimensional finiteelement model of heat transfer in complete fenestration systems. ASHRAE Transactions: Symposia 1207-1220 (1994).
[7] R. E. Collins, T. M. Simko, Current status of the sciences and technology of vacuum glazing, Solar Energy, 62, 189-213 (1998).

[8] Y. Fang, P. C. Eames, The effect of glass coating emittance and frame rebate on the heat transfer through vacuum and electrochromic vacuum glazed windows, Solar Energy Material and Solar Cells, 90, 2683-2695, (2006).

[9] Y. Fang, P.C. Eames, B. Norton, T.J. Hyde, Experimental validation of a numerical model for heat transfer in evacuated glazing, Solar Energy 80, 564-577, (1996).

[10] P. C. Eames, B. Norton, A validated unified model for optics and heat transfer in line-axis concentrating solar energy collectors, Solar Energy 50, 339-355 (1993).

[11] Q.-C., Zhang, T. M. Simko, C.J. Dey, R. E., Collins, G. M. Turner, M. Brunotte, A. Gombert, The measurement and calculation of radiative heat transfer between uncoated and doped tin oxide coated glass surfaces. The measurement and calculation of radiative heat transfer between uncoated and doped tin oxide coated glass surfaces. Int. J. Heat and Mass Transfer 40, 61-71 (1997).

[12] ASTM, 1991. Standard procedures for determining the steady state thermal transmittance of fenestration systems, ASTM Standard E 1423-91. In 1994 Annual Book of ASTM Standard 04.07. American Society of Testing and Materials, 1160-1165.

[13] J.P. Holman, Heat Transfer (SI Metric Edition), McGraw-Hill, 1989.

[14] C. F. Wilson, T.M. Simko and R.E.Collins, Heat conduction through the support pillars in vacuum glazing. Solar Energy, 63 (6), 393 - 406, 1998.

[15] Y. Fang, P.C. Eames, T.J. Hyde, B. Norton, Complex multimaterial insulating frames for windows with evacuated glazing. Solar Energy 79 245-261 (2005).

[16] Y. Fang, P.C. Eames, B. Norton, The effect of glass thickness on the thermal performance of evacuated glazing. Solar Energy 81, 395-404 (2007).

[17] ISO, Thermal insulation - Determination of steady-state thermal transmission properties - Calibrated and guarded hot box. (ISO 8990) International Standards Organization, Geneva, Switzerland (1994). 